\title{
Tube-in-basket burner for rice husk. II: Performance of TiB burners
}

\author{
P C KAPUR,* P P SINGH* and S SESHADRI $\dagger$ \\ Tata Research Development \& Design Centre, 1, Mangaldas Road, Pune 411 001, India \\ *Indian Institute of Technology, Kanpur 208016 \\ MS received 28 May 1984; revised 27 September 1984
}

\begin{abstract}
Three working models, TiB MK II, MK IIK and III, capable of continuous combustion, are described. It is shown that these burners can be operated continuously in a stable pseudo-steady-state manner by means of intermittent charging of husk from the top and discharging of ash from the bottom. Mass and heat balance data, flame temperatures, combustion efficiencies and heat transfer efficiencies for heating water in a vessel are included. Combustion efficiency of about $72 \%$ was achieved in TiB MK II by making a significant change in the basket design, the lower half being made conical. The efficiency was boosted further to roughly $82 \%$ in MK IIK by extending the bottom rim of the cone straight down by an additional $7.5 \mathrm{~cm}$ and replacing the upper basket cylinder by a fully enclosed box. A water heating jacket was also incorporated in this model around the upper end of its bumer tube. This modification resulted in a highly efficient water heating or steam raising device. Comparison with step-grate furnaces shows that TiB burners have similar or superior performance characteristics with additional advantages of simplicity, compactness and low cost.
\end{abstract}

Keywords. Husk burner; design; burner performance; heat transfer; mass transfer; thermal efficiency.

\section{Introduction}

The essential soundness of the TiB burner concept was demonstrated in the first part of this communication (Kapur et al 1984). The objective of this part is to describe the design and performance of three working TiB models which operate in a continuous combustion mode with intermittent charging of husk from the top and discharging of ash from the bottom.

\section{TiB MKII (continuous burner)}

Based on experience gained on the TiB MK I batch burner described in the previous part, this model was modified with respect to two important aspects (figure I).

(i) the lower half of the basket was conical. In other words, the radial width to chimney height ratio was made variable; it changed from $1 / 4$ in the cylindrical upper portion of the basket to $1 / 7$ at the bottom of the cone. This was done to force disproportionately more air through the bottom portion of the husk char bed in order to burn off as much combustible matter as possible before the ash is discharged.

†For correspondence. 


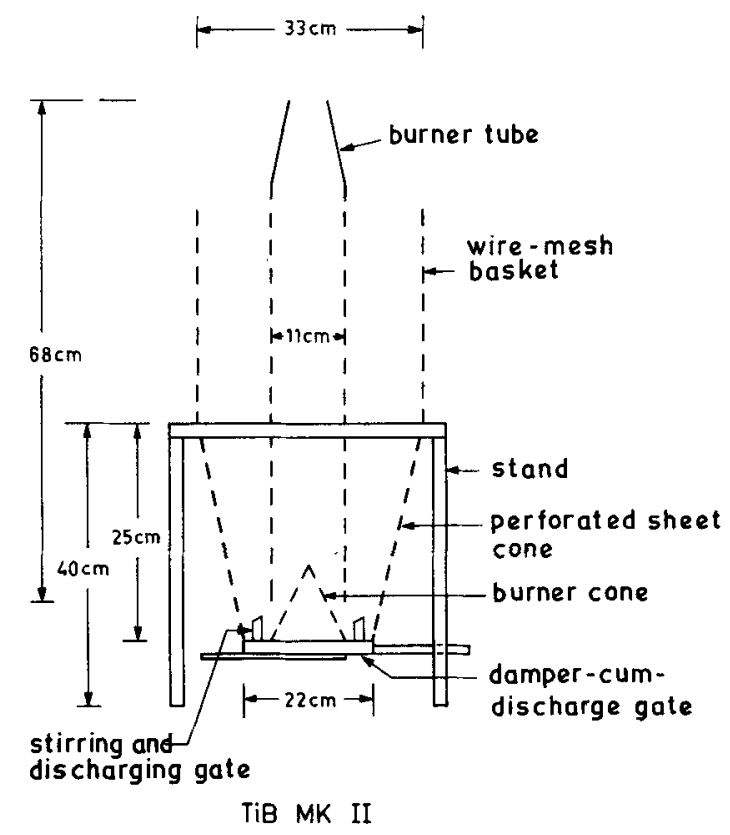

Figure 1. Design of TiB MK II continuous rice husk burner

(ii) a composite damper-discharge assembly was designed and fitted to the lower end of the basket which combined the following three functions: (a) controlled inlet of secondary air through the bottom opening of the burner tube; (b) stirring and agitation of ash bed; (c) discharge of ash from annular section between the tube and the basket.

Engineering drawings and fabrication details of TiB MKII and the other two models are not included in the present report.

The performance of TiB MKII was studied and analysed. The results are given in the following sections.

\subsection{Rice husk}

Rice husk used in these experiments had the following characteristics:

(a) source-sheller rice husk; (b) Moisture content ( $4 \mathrm{hr}$ at $100^{\circ} \mathrm{C}$ ) $-8 \%$; (c) loose bulk density of dry husk-103 $\mathrm{kg} \mathrm{m}^{-3}$; (d) ash content (as received basis) $-18.4 \%$, (dry basis) $-20 \%$.

\subsection{Starting procedure}

A correct lighting procedure was found necessary for proper functioning of the TiB. Rice husk was poured uniformly through the annular space between the tube and the basket to a depth of about $10 \mathrm{~cm}$. A small piece of rag was soaked in kerosene oil, set on fire and lowered with a wire down the burner tube onto the bed of husk. In a minute or two, the surrounding husk began to char and liberate volatile matter. These volatiles were pulled into the tube by the suction generated by the chimney and began to burn with a steady flame inside the tube. At this point, the basket was filled to the top with husk and the rag was pulled out. TiB was now lit. The secondary air damper was adjusted to give the best possible flame as judged by visual observation. 


\subsection{Continuous operation of TiB}

Within about 10 minutes of lighting the TiB, a glowing fire bed was observed through the perforation at the bottom portion of the cone. This fire zone gradually moved upward. Ash or char was discharged periodically to keep the fire zone in the middle portion of the cone. The discharging and stirring actions occurred simultaneously. This is because the fingers which swept ash into the discharge openings also broke up the ash lumps and bridges and thereby permitted a smooth and uniform settling of the bed. The level of rice husk in the upper cylindrical basket fell as husk at the bottom was turned into ash and discharged. More husk was added periodically whenever the bed level fell below the rim of the basket. With some practical experience, no difficulty was encountered in running $\mathrm{TiB}$ in a psuedo-steady state, as described below.

Figure 2 gives data for a typical 150 minutes continuous run carried out at a fast firing rate, ie rapid discharge of char with little regard for burning out all the combustibles in husk. The data includes batch weights of husk fed and ash taken out at the indicated

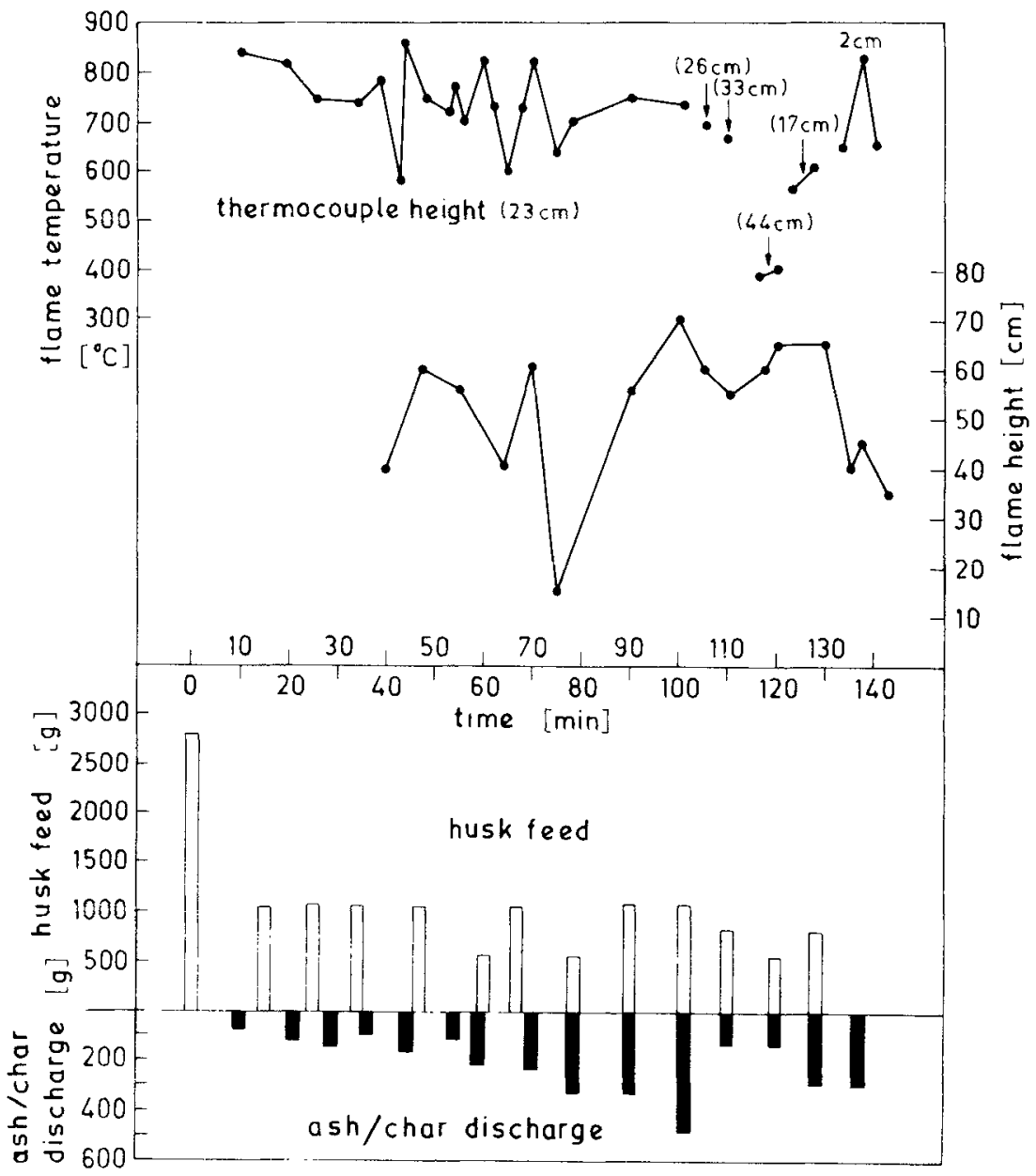

Figure 2. Operational data for TiB MK II over a continuous run of 150 minutes, comprising husk feed, char discharge, flame temperature and its visible height 
times, visible flame height above the burner tube and the flame temperature in open air, as measured with a thermocouple inserted at different heights above the tube mouth. The flame temperature measured at $23 \mathrm{~cm}$ height fluctuated around $750^{\circ} \mathrm{C}$ with extreme values of almost $900^{\circ} \mathrm{C}$ and $600^{\circ} \mathrm{C}$. On most occasions, the temperature shot up whenever the ash or char was taken out. This presumably was due to sliding down of fresh husk into the hot cone which in turn caused rapid liberation of volatile matter, as well as disturbance of bed by the stirrers which released the volatile matter trapped in the inter-particle void space. On the other hand, except for a small time interval, the flame height remained relatively constant. A band of temperatures at different heights in the flame measured in the course of many runs is shown in figure 3. As anticipated, the temperature dropped with increase in height due to loss of heat by radiation and ingress of surrounding cold air into the flame.

Figure 4 shows the cumulative amount of husk added and ash discharged as a function of time. From the rather remarkable straight line plots obtained, it is concluded that TiB can be easily operated in a stable and steady mode by visual observation of the fire zone and fiame only. Moreover, it takes 10-20 minutes to attain the psuedo-steady state with respect to husk feed and 30-40 minutes with respect to ash discharge. From the slopes of the straight line plots the following results were computed:

(i) Average husk feed rate:

(ii) Average char discharge rate:

$5 \cdot 29 \mathrm{~kg} \mathrm{hr}^{-1}$ (as received basis) $1.60 \mathrm{~kg} \mathrm{hr}^{-1}$.

These values were used for the mass and heat balance computations described below

\subsection{Mass balance}

From the feed and discharge rates, it is possible to carry out mass and heat balance around the combusted matter (CM), unburnt combustible matter (UCM) and mineral ash (MA). (All computations are on dry husk and per hour basis).

(a) Husk feed (as received):

$5 \cdot 29 \mathrm{~kg}$,

(b) Husk feed (dry basis):

$$
5 \cdot 29 \times(92 / 100)=4.87 \mathrm{~kg} \text {, }
$$

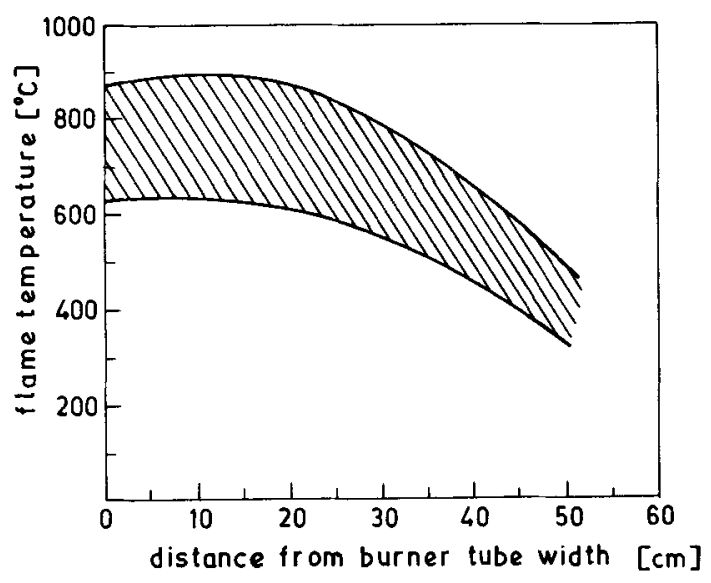

Figure 3. Range of flame temperatures in TiB MK II burner as a function of height above the mouth of the burner tube. Data combined from a number of runs 


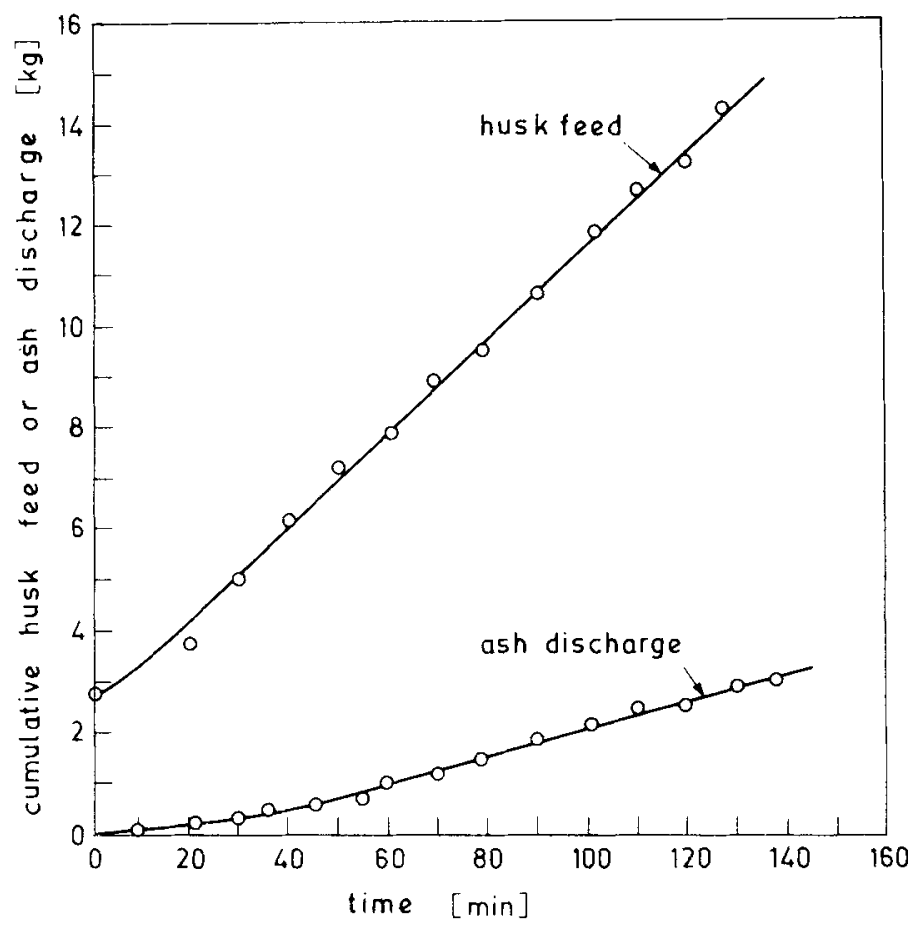

Figure 4. Cumulative husk added and char removed as a function of time for TiB MK II burner

(c) Char discharged:

(d) Combusted matter, $\mathrm{CM}$ (by difference):

(e) Mineral ash, ma in char:

(f) Unburnt combustible matter in char, UCM (by difference):

(g) $\%$ of husk feed discharged as char:

(h) $\%$ UCM in char:
$1 \cdot 60 \mathrm{~kg}$

$$
\begin{aligned}
& 4.87-1.60=3.27 \mathrm{~kg}, \\
& 4.87 \times(20 / 100)=0.974 \mathrm{~kg}, \\
& 1.60-0.974=0.626 \mathrm{~kg} \\
& (1.6 / 4.87) \times 100=32.85 \\
& (0.626 / 1.6) \times 100=39 \cdot 12
\end{aligned}
$$

\subsection{Heat balance and combustion efficiencies}

Assuming calorific value, $\mathrm{cv}$, of dry husk is $14.63 \mathrm{MJ} \mathrm{kg}^{-1}\left(3500 \mathrm{kcal} \mathrm{kg}^{-1}\right)$, the heat balance is given by:

$$
4.87 \times 14.63=3.27(\mathrm{cv})_{\mathrm{CM}}+0.626(\mathrm{cV})_{\mathrm{UCM}}+0.974(\mathrm{cV})_{\mathrm{MA}} \text {. }
$$

Since the mineral ash component has no combustibles, its calorific value is zero ie $(\mathrm{CV})_{\mathrm{MA}}=0$, and thus the potential heat in husk is split between $\mathrm{CM}$ and UCM. The calorific value of UCM is not known. Indeed, it has no fixed value since its chemical and physical nature (wood-tar content, $\% \mathrm{H}$, state of crystallinity of carbon, etc) would depend on the time and temperature of thermal treatment that the rice husk has undergone. On heating, first the large cellulose and lignin molecules of the wood undergo thermal degradation and the smaller fragments are liberated as volatile matter, leaving behind 
the tar. At higher temperatures, the tar polymerizes progressively towards a poorly crystalline form of carbon. True crystalline carbon (graphite) is formed only above $2500^{\circ} \mathrm{C}$. It is evident that the calorific value of UCM in char would be higher, greater the thermal treatment it has been subjected to (which also means smaller the \% of UCM in the ash). In order to carry out a heat balance between $\mathrm{CM}$ and UCM, two values for the calorific value of UCM were assumed:

(a) Since both charcoal and UCM were formed by pyrolysis of woody matter, it is assumed that their calorific values would be comparable. After correcting for its ash content, the calorific value of charcoal is about $29.26 \mathrm{MJ} \mathrm{kg}^{-1}\left(7000 \mathrm{kcal} \mathrm{kg}^{-1}\right)$ and this value was assigned to it.

(b) On the other extreme, UCM was assumed to be almost pure carbon and its calorific value was arbitrarily fixed at $35.53 \mathrm{MJ} \mathrm{kg}^{-1}\left(8500 \mathrm{kcal} \mathrm{kg}^{-1}\right)$, the same as anthracite coal.

Substitution in (1) gives the calorific value of CM. Efficiency of combustion $\left(E_{c}\right)$ can then be calculated thus:

$$
E_{c}=\frac{3.27(\mathrm{cv})_{\mathrm{CM}}}{4.87 \times 14.63} \times 100 \% \text {. }
$$

The table below gives the results:

\begin{tabular}{|c|c|c|}
\hline & Assumption (a) & Assumption (b) \\
\hline CV of dry husk & $14.63 \mathrm{MJ} \mathrm{kg}^{-1}$ & $14.63 \mathrm{MJ} \mathrm{kg}^{-1}$ \\
\hline $\mathrm{CV}$ of UCM (assumed) & $29 \cdot 26 \mathrm{MJ} \mathrm{kg}^{-1}$ & $35.53 \mathrm{MJ} \mathrm{kg}^{-1}$ \\
\hline $\mathrm{CV}$ of $\mathrm{CM}(1)$ & $16 \cdot 24 \mathrm{MJ} \mathrm{kg}^{-1}$ & $15.05 \mathrm{MJ} \mathrm{kg}^{-1}$ \\
\hline$E_{c}(2)$ & $74.5 \%$ & $69.9 \%$ \\
\hline$E_{c}($ mean $)$ & $72 \cdot 2 \%$ & \\
\hline
\end{tabular}

Thermal output $=4.87 \times 14.63 \times 0.722=51.46 \mathrm{MJ} \mathrm{h}^{-1}$ or $14.3 \mathrm{~kW}$. TiB gives satisfactory combustion efficiency even with a less favourable value for $(\mathrm{CV})_{\mathrm{ucm}}$. Note that these efficiencies are for the case when $\mathrm{TiB}$ was run at a fast firing rate with a short residence time of husk in the basket. Significantly higher efficiency should be attainable at a slower rate of firing, which would reduce the \% UCM in ash.

\subsection{Heat transfer to vessel}

For heat transfer studies, water was heated on a TiB in a vessel kept in the open at different heights above the burner tube under the following conditions:

Vessel:

Diameter: $\quad 34 \mathrm{~cm}$

Height: $\quad 18 \mathrm{~cm}$

Water: $\quad 3 \mathrm{~kg}$

Initial temperature: $22^{\circ} \mathrm{C}$

Heating of water was started 45 minutes after lighting TiB in order to ensure steady state conditions. Temperature of water was monitored continuously. Figure 5 shows the time taken to heat water from 30 to $90^{\circ} \mathrm{C}$ and from 40 to $90^{\circ} \mathrm{C}$ as a function of vessel height above the burner tube. From these curves, it is concluded that the optimal height 


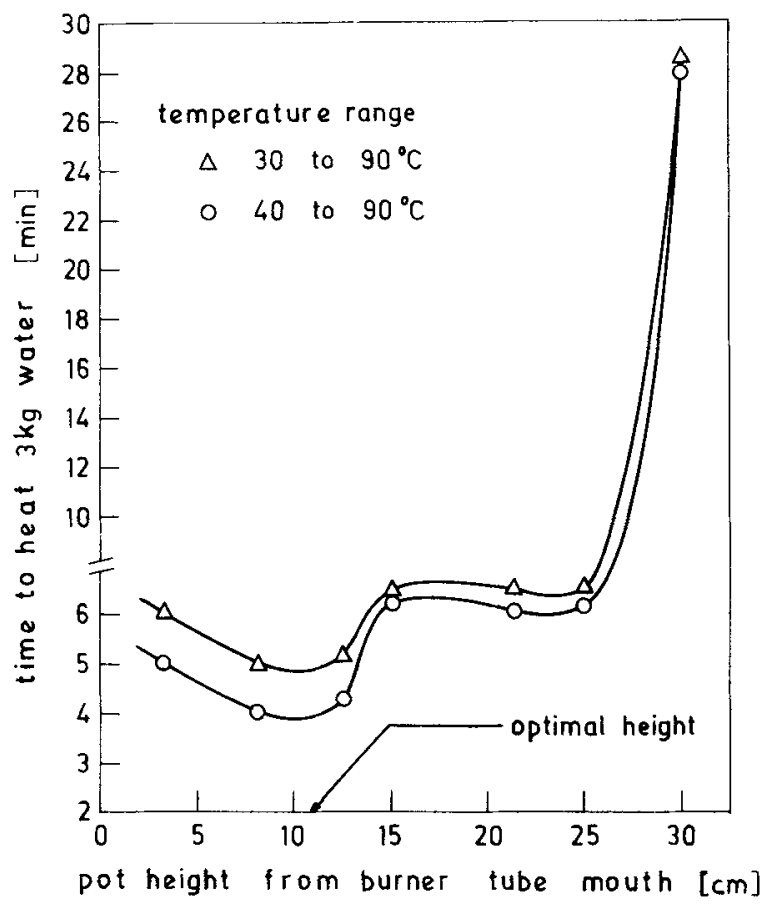

Figure 5. Time taken to heat $3 \mathrm{~kg}$ water through 30 to $90^{\circ} \mathrm{C}$ and 40 to $90^{\circ} \mathrm{C}$ at different vessel heights above the burner tube of TiB MK II burner

was about $11 \mathrm{~cm}$ where it took 4 minutes and 45 seconds to heat $3 \mathrm{~kg}$ water from 30 to $90^{\circ} \mathrm{C}$ and 4 minutes to heat it from 40 to $90^{\circ} \mathrm{C}$.

The overall efficiency of heat transfer from potential energy in husk to energy supplied to water is,

$$
E_{\mathrm{ot}}=\frac{\text { energy supplied to heat water from } 30 \text { to } 90^{\circ} \mathrm{C}}{\text { potential energy in husk consumed in } 4.75 \mathrm{~min}} \times 100 \text {, }
$$

or $\quad E_{\text {ot }}=13.34 \%$.

The net heat transfer efficiency is,

$$
\begin{aligned}
& E_{\mathrm{nt}}=\frac{\text { energy supplied to heat water from } 30 \text { to } 90^{\circ} \mathrm{C}}{\text { energy liberated from husk }}, \\
& \text { or } \quad E_{\mathrm{nt}}=\frac{E_{\mathrm{ot}} \times 100}{E_{c}}=\frac{13.34 \times 100}{72.2}=18.5 \%
\end{aligned}
$$

A practical index of cost, $C_{\mathrm{p}}$, convenient for the purpose of comparison, is defined as kilograms of dry husk consumed to raise one $\mathrm{kg}$ water through $1^{\circ} \mathrm{C}$ temperature range. For TiB MKII, $C_{p}=2.14 \times 10^{-3} \mathrm{~kg} \mathrm{~kg}^{-1}{ }^{\circ} \mathrm{C}^{-1}$.

A few comments are in order here. (i) The modest heat transfer efficiencies obtained, in spite of the reasonably satisfactory combustion efficiency, points to the need for a better heating arrangement, eg larger vessel diameter, wind shield, etc. (ii) Again these results pertain to fast firing of $\mathrm{TiB}$, with a flame temperature of about $750^{\circ} \mathrm{C}$. The efficiencies could be improved with a somewhat slower rate of firing. (iii) Computation 
of efficiencies did not include the heat content of the vessel (whose average temperature is significantly higher than water). This correction would boost $E_{\text {ot }}$ by nearly $1.5 \%$. (iv) A vessel of smaller capacity would have given somewhat better efficiencies ( $K$ Krishna Prasad 1984, private communication)

\section{TiB MK IIK}

In some of the traditional rice growing states of the country, eg Andhra Pradesh, rice husk is widely and routinely used for community cooking on the miniaturised version of the step-grate type furnace with all the disadvantages which are associated with this combustion system. It was therefore felt that there was a definite need for a selfcontained TiB burner tailor-made for cooking in large households, small/medium size restaurants, hostels, etc. Based on experience gained from field trials, the TiB MK IIK kitchen model was designed to serve this purpose, and it differed from TiB MKII in that it had (figure 6):

(i) An extra $7.5 \mathrm{~cm}$ high straight cylindrical extension (also perforated) at the bottom of the cone in order to increase the air flow rate into the char bed, which improves the combustion efficiency as well as the rate of combustion of husk.

(ii) A fully enclosed square box with a husk feed opening, in place of the upper cylindrical basket, for eliminating any possible smoking from the surface of the husk bed and to dry and heat up the husk before it slides down into the combustion zone. (iii) A water circulating box jacketed around the upper end of the burner tube for continuous supply of hot water or steam.

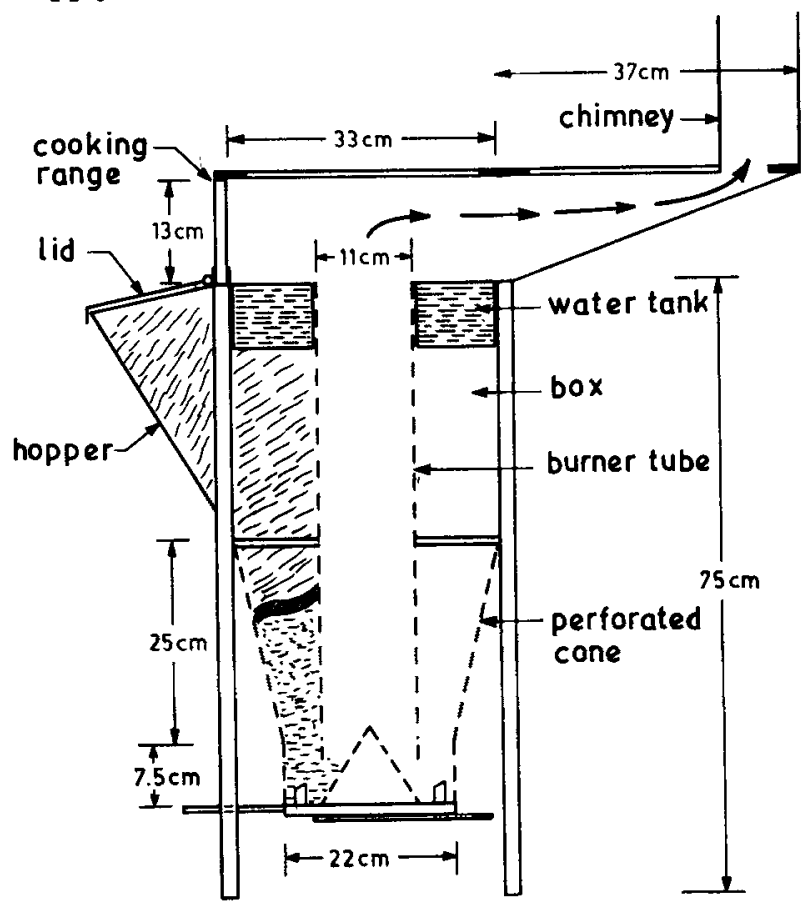

TiB MK IIK

Figure 6. Design of TiB MK IIK husk burner 
(iv) A side plate under which the combustion gases were deflected and then vented to the atmosphere through a chimney thereby providing a second cooking station, in addition to the main cooking slot above the burner mouth. The vessel and the heating conditions were the same as before except that the pot contained $7 \mathrm{~kg}$ water and the jacketed box contained $9.8 \mathrm{~kg}$ water. The performance results are summarised in the following sections.

3.1 Mass balance (per hour basis)

(a) Husk feed (as received)

(b) Husk feed (dry basis) $(6.13 \times 92) / 100=$

(c) Ash/char discharged

$6 \cdot 13 \mathrm{~kg}$,

$5.64 \mathrm{~kg}$,

$1.60 \mathrm{~kg}$,

$5.64-1.60=4.04 \mathrm{~kg}$,

$1.60-(5.64 \times 20 / 100)=0.47 \mathrm{~kg}$,

(e) Unburnt combustible matter in char, UCM

(f) $\%$ of husk feed discharged as ash/char

(g) $\%$ UCM in ash/char

\subsection{Heat balance and combustion efficiencies}

The heat balance equation is:

$$
5.64 \times 14.63=4.04(\mathrm{cV})_{\mathrm{CM}}+0.47(\mathrm{CV})_{\mathrm{UCM}}
$$

and the efficiency of combustion is:

$$
E_{c}=\frac{4.04(\mathrm{cv})_{\mathrm{cM}}}{5.64 \times 14.63} \times 100 .
$$

Therefore as argued in $\$ 2.5$ :

$$
\begin{aligned}
& E_{\mathrm{c}}=83.3 \% \text { on the assumption }(\mathrm{cv})_{\mathrm{UCM}}=29.26 \mathrm{MJ} \mathrm{kg}^{-1}, \\
& E_{c}=79.8 \% \text { on the assumption }(\mathrm{CV})_{\mathrm{UCM}}=35.53 \mathrm{MJ} \mathrm{kg}^{-1} \text {, } \\
& E_{\mathrm{c}} \text { (mean) }=81.6 \%
\end{aligned}
$$

Thermal output $=18 \cdot 6 \mathrm{~kW}$.

\subsection{Heat transfer to vessel}

Since water in the pot and the jacket heated up at different rates, it is not possible to determine how heat is partitioned between the two containers. Therefore, the heat transfer efficiencies had to be computed in a different manner as follows:

Time to heat $7 \mathrm{~kg}$ water in the pot through

40 to $90^{\circ} \mathrm{C}$ :

Mean heat transfer rate to the pot:

Time to heat $9.8 \mathrm{~kg}$ water in the jacket through 40 to $90^{\circ} \mathrm{C}$ :

Mean heat transfer rate to the jacket:

Overall mean heat transfer rate to both vessels:
$17 \mathrm{~min}$,

$(7 \times 50 \times 1) / 17$

$=20.59 \mathrm{kcal} \mathrm{min}^{-1}$,

$8 \mathrm{~min}$,

$(9.8 \times 50 \times 1) / 8$

$=61.25 \mathrm{kcal} \mathrm{min}^{-1}$,

$81.84 \mathrm{kcal} \mathrm{min}^{-1}$

or $0.342 \mathrm{MJ} \mathrm{min}^{-1}$. 
The overall efficiency of heat transfer is:

$$
\begin{aligned}
E_{\mathrm{ot}} & =\frac{\text { heat transfer to water per minute }}{\text { potential energy in husk feed per minute }} \\
\text { or } \quad E_{\mathrm{ot}} & =\frac{0.342 \times 60}{5.64 \times 14.63} \times 100=24.9 \%
\end{aligned}
$$

and the net heat transfer efficiency is:

$$
E_{\mathrm{nt}}=\frac{E_{\mathrm{ot}} \times 100}{E_{\mathrm{c}}}=\frac{24.9}{81.6} \times 100=30.5 \% \text {. }
$$

Similarly, the practical index of cost $C_{p}$ is computed in the following manner:

$$
\begin{aligned}
& \text { temperature rise of water per minute: } 81.84 /(1 \times 16.8)=4.87^{\circ} \mathrm{C} \text {, } \\
& C_{p}=(5.64 / 60) \times(1 / 4.87) \times(1 / 16.8)=1.15 \times 10^{-3} \mathrm{~kg}^{-1} \mathrm{~kg}^{\circ} \mathrm{C}^{-1} \text {. }
\end{aligned}
$$

From the performance data on TiB MK IIK it will be seen that the efficiency of combustion is nearly $82 \%$ as compared to $72 \%$ for TiB MKII. It is significant that forced draft by blowers is required to attain comparable combustion efficiency in the step-grate furnaces. This improvement occurs inspite of a higher dry husk feed rate of $5.64 \mathrm{~kg} \mathrm{hr}^{-1}$ as against $4.87 \mathrm{~kg} \mathrm{hr}^{-1}$. This is attributed to design modification relating to cylindrical extension of the cone. The cost index $1.15 \times 10^{-3} \mathrm{~kg}$ of husk needed to raise the temperature of one $\mathrm{kg}$ water by $1^{\circ} \mathrm{C}$, is exceptionally low. This means that $\mathrm{TiB}$ MK IIK should be an attractive heat module not only for large scale cooking purposes, but also for processes requiring hot water or steam, eg, parboiling of rice. Indeed this TiB has been successfully used for demonstration in a number of restaurants for cooking food and obtaining boiling water for hot beverages and washing utensils. In case hot water is not required, the water container can be dispensed with at significant cost benefit.

\section{TiB MK III (larger version)}

As shown in figure 7, TiB MK III is a larger version for higher heat output. It differs significantly from TiB MKII and MK IIK in the basket design. It was meant primarily for providing process heat in small scale industries and post-harvest processing. Typical performance data on an hourly basis is summarised below:

(a) Husk feed (as received)

(b) Husk feed (dry basis)

(c) Char

(d) Combusted matter, $\mathrm{CM}$

(e) Mineral ash in char

(f) Unburnt combustible matter in char, UCM

(g) $\%$ UCM in char
$10 \cdot 3 \mathrm{~kg}$, $9.46 \mathrm{~kg}$, $3.6 \mathrm{~kg}$, $9.46-3.6=5.86 \mathrm{~kg}$, $1.89 \mathrm{~kg}$, $3.6-1.89=1.71 \mathrm{~kg}$, $47.5 \%$

Hence the heat balance is:

$$
9.46 \times 14.63=5.86 \times(\mathrm{cv})_{\mathrm{CM}}+1.71(\mathrm{CV})_{\mathrm{CM}} \text {. }
$$




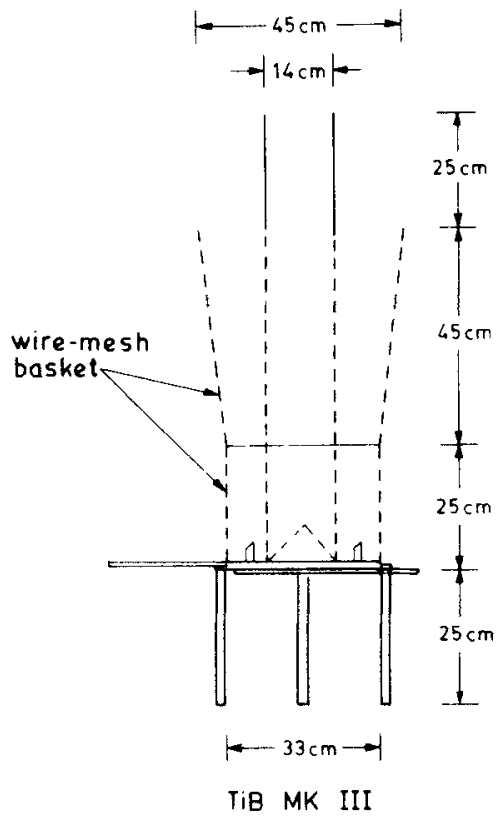

Figure 7. Design of TiB MK III husk burner

Therefore:

or

$E_{\mathrm{c}}=63.9 \%$ under assumption (a),

$E_{c}=56.1 \%$ under assumption (b),

$E_{c}($ Mean $)=60 \%$.

Thermal output $=23 \cdot 1 \mathrm{~kW}$

$$
C_{p}=1.93 \times 10^{-3} \mathrm{~kg} \mathrm{~kg}^{-1 \circ} \mathrm{C}^{-1} \text {. }
$$

\section{Discussion}

A comparison of the performance of the three TiB models MK II, MK IIK and MK III is instructive (table 1). The major design difference between the first and the last models is the cone which is absent in MK III. It would seem that the cone plays an important role in improving the combustion efficiency significantly from $60 \%$ to $72 \%$, (i) by forcing the charge to intermingle as it slides down and (ii) permitting greater volumes of air to pass through the fire bed at the bottom of the cone and thereby burn off a higher percentage of the combustible matter in the char. Even greater improvement is possible as in the MK IIK design where the upper cylindrical basket is replaced by a fully enclosed box and the cone bottom rim is extended straight down by $7.5 \mathrm{~cm}$. The box maintains the chimney at a higher temperature leading to a more powerful draft, and the bottom extension permits a longer residence time of char in the combustion zone for a more complete burn-off of the combustibles. As a consequence, now a combustion efficiency of approximately $82 \%$ is attainable.

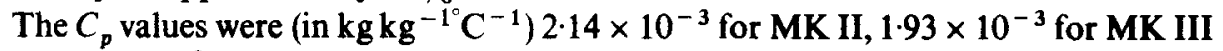
and $1.15 \times 10^{-3}$ for MK IIK. Comparison with $C_{p}$ of a scientifically designed step-grate 
Table 1. Comparison of three models of TiB

\begin{tabular}{|c|c|c|c|c|}
\hline Parameter & Units & MK II & $\begin{array}{l}\text { TiB Model } \\
\text { MK IIK }\end{array}$ & MK III \\
\hline Average husk feed rate (as received) & $\mathrm{kghr}^{-1}$ & $5 \cdot 29$ & $6 \cdot 13$ & $10 \cdot 3$ \\
\hline Average char discharge rate & $\mathbf{k g ~ h r}^{-1}$ & 1.60 & 1.60 & 3.6 \\
\hline $\begin{array}{l}\% \text { husk feed, discharged as char } \\
\% \text { Unburnt combustible matter }\end{array}$ & & 33 & 28 & \\
\hline (UCM) & & 39 & 29 & $47: 5$ \\
\hline Efficiency of combustion & $E_{c} \%$ & $72 \cdot 2$ & $81 \cdot 6$ & 60 \\
\hline Thermal output & $\mathbf{k W}$ & $14 \cdot 3$ & $18 \cdot 6$ & $23 \cdot 1$ \\
\hline \multicolumn{5}{|l|}{ Overall efficiency of heat transfer to } \\
\hline water & $E_{\mathrm{ot}} \%$ & $13 \cdot 3$ & $24 \cdot 9$ & \\
\hline Net heat transfer efficiency & $E_{\mathrm{nt}} \%$ & 18.5 & 30.5 & \\
\hline$C_{p}$ & $\begin{array}{l}10^{-3} \mathrm{~kg} \\
\mathrm{~kg}^{-1}{ }^{\circ} \mathrm{C}^{-1}\end{array}$ & $2 \cdot 14$ & $1 \cdot 15$ & 1.93 \\
\hline
\end{tabular}

test furnace is revealing (Singh et al 1980). For heating $300 \mathrm{~kg}$ water, $C_{p}$ value was estimated as $1.88 \times 10^{-3} \mathrm{~kg} \mathrm{~kg}^{-1^{\circ}} \mathrm{C}^{-1}$, comparable with that of TiB MK II and III, and significantly higher than TiB MK IIK. This is despite the fact that the amount of water heated on the step-grate furnace was considerably more (and efficiency is inherently favoured by larger scale) and the combustion chamber was fully enclosed and the vessel was sunk into the chamber for more efficient heat transfer.

\section{Concluding remarks}

It is conceded that the combustion efficiency calculations are subject to some uncertainty as the exact calorific value of UCM in char could not be determined due to the absence of experimental facilities, and had to be assumed. However by taking a range of values for the CV of UCM, it has been possible to make a reasonable estimate of the combustion efficiencies. For TiB MKII and IIK the combustion efficiencies are quite satisfactory. The efficiency is relatively low in case of TiB MK III, but it is not unreasonable to expect that a marked improvement should be possirle by substituting a cone in the lower half of the basket.

TiB is essentially a single power level burner in view of the fact that the secondary air valve does not seem to affect the rate of pyrolysis of husk. However, the control provided by this valve is useful for taking care of variations in the husk and its moisture content, etc.

Note that the TiB burner is essentially a compact heat module. A number of these modules can be easily joined together to meet a given quantum of energy need. In fact in many applications, multiport entry of hot combustion gases should lead to a more uniform heating than through a single port entry. Also, TiB flame is relatively clean, almost free of particulate matter. Therefore, direct heating, without the use of heat exchangers, may be possible in those applications where the product quality is not very sensitive to contamination.

Finally it is stressed that TiB has considerable scope for design modification and improvement. There is also a need for fundamental studies on heat and mass transfer, and flame dynamics in relation to $\mathrm{TiB}$ for a better understanding of its operations and optimising the design. 
The authors are grateful to E. C. Subbarao for valuable discussions.

\section{References}

Kapur P C, Singh R, Srinivasan J 1984 Sādhanā 7: 291-300

Singh R, Maheshwari R C, Ojha T P 1980 Agricultural Mechanisation in Asia, Autumn: 31-37 